\title{
Continuous Power Flow and Time Domain Analysis for Assessing Voltage Stability
}

\author{
Wiwin A. Oktaviani ${ }^{1}$, Taufik Barlian ${ }^{2}$, Yosi Apriani ${ }^{3}$ and Nugraha Syarif ${ }^{4}$ \\ 1,2,3,4 Program Studi Teknik Elektro, Universitas Muhammadiyah Palembang \\ Jalan Jenderal Ahmad Yani Kecamatan Plaju, Palembang, Indonesia \\ Email:wiwin_oktaviani@um-palembang.ac.id
}

\begin{abstract}
Voltage instability is considered one of the primary sources of insecurity in power systems. Voltage instability is the phenomenon in which the voltage on the receiver's side is dropping far below the normal value and does not return even after establishing a voltage recovery mechanism, or continue to oscillate due to lack of attenuation. In this study, there will be a voltage stability analysis on the power system in several phases, i.e., a power flow analysis, static voltage stability analysis using continuous power flow method, and dynamic voltage stability analysis using the time-domain analysis. The power system tested on this research is the IEEE 6 bus system from Wood \& Wollenberg, with the software used for the simulation, which is PSAT. The results show that voltage stability analysis using Continuous Power Flow and Time Domain Analysis can provide a more comprehensive overview of a power system stability level. The highest decrease in voltage with a value of $1.5 \%$ appears in Bus 5, which is also suffering the lowest stability level. The system has a load margin $(\lambda)$ value of 1.6130 a clearing time of under 0.4 seconds
\end{abstract}

Keywords - Static Voltage Stability Analysis, Dynamic Voltage Stability Analysis, Continuous Power Flow, Time Domain Analysis, PSAT

\section{INTRODUCTION}

Voltage stability analysis is the one effort to maintain continuity and availability of electrical energy supply to the consumer [1], [2]. It is to maintain the operating conditions of an electrical power system to be stable by fulfilling various operating criteria and must be[3]-[7] safe in case of possible situations out of range. For that, the power system should be operated far from the limits of its stability, so that at the time of disruption, the system has sufficient operational area limit to recover its state [8], [9]. However, current energy systems are often operated close to the limits of stability due to economic and environmental constraints. Maintaining this stability is a challenge in the operation of power systems [10], [11].

Voltage instability can result in the inability of the generator and transmission to provide power on demand loads. The cause may result from equipment outages and limitations of reactive power supplies or due to increased sharp loads. Therefore, the generator reactive power limit must take into account. The Phasor Measurement Unit (PMU) method can handle the Q limit.
Furthermore, load characteristics are also given a significant impact on power system stability analysis. Therefore, it is necessary to obtain an accurate load model in digital simulation. The load increment can affect the voltage stability index, especially in the transmission line. If there is a transmission contingency, the system will get closer to voltage instability [12], [13].

Voltage stability also depends on the initial condition of the system [14]-[16]. Voltage dynamic stability estimation can be done by applying voltage time-series data, known as the maximum Lyapunov exponent. This method gives a proper evaluation for dynamic voltage stability in a short time but not for a more extended period.

Several stages of analysis have done to get an overview of the voltage stability in a power system, which are; Analysis of system power flows, static voltage stability analysis, and dynamic voltage stability analysis. Simulated results on the tested power system are presented to illustrate the voltage stability issues and basic methods for analyzing the problem.

In the AC transmission system, the Unified Power Flow Controller (UPFC) has been used widely to overcome voltage instability [17]-[19]. By optimizing the UPFC location, followed by applying the Equivalent Current Injection power flow model in Power System Analysis, the voltage stability index decreased [20]-[22]. Therefore, the voltage stability margin will improve.

Besides UPFC, Power System Stability (PSS) can be applied to improve voltage stability to some extent. The use of PSS on the 11 bus system not too influential to dynamic stability.

One of the research proposed Continuous Power Flow (CPF) to analyze voltage stability in the micro-grid system [10], [23]-[26]. The relationship between Distribute Generator placement and its effect on the voltage stability can also explain using this method.

Previous studies described previously were conducted to observe voltage stability in only one state. In this study, voltage stability under normal, static, and dynamic conditions was investigated. Power flow analysis is performed to see the voltage drop on each bus for normal conditions [27]. Static voltage stability analysis is carried out to observe the voltage stability when the system experiences a periodic load increase. Meanwhile, dynamic voltage stability analysis conducted to see the voltage stability when the system is experiencing disturbance.

All analyses conducted on this research were performed using the PSAT software in MATLAB, and the systems tested 
were the electrical system of the IEEE 6 Bus. Static voltage stability analysis is done using the continuous power flow method, while dynamic security stability analysis is conducted using the time-domain analysis.

\section{LITERATURE STUDIES}

\section{A. Transmission Line}

In the electric power network, the interconnection system is common because the utilization of network interconnection will increase reliability and can enlarge the resulting power supply. The interconnection system is the development of a network or mesh system. This system distributes the electric power of some of the desired power plant centers. It works in parallel so that the transmission of electrical power can take place continuously (unbroken) despite the high load density in one or several points/areas within the network. In this interconnection system, when one of the power plant centers is damaged, electricity transmission can be transferred to another plant center. For the center of plants that have small capacity is usually used as a helper of the main plant center that has a larger power capacity. An example of an interconnection system of electrical power systems can be seen in Figure 1.

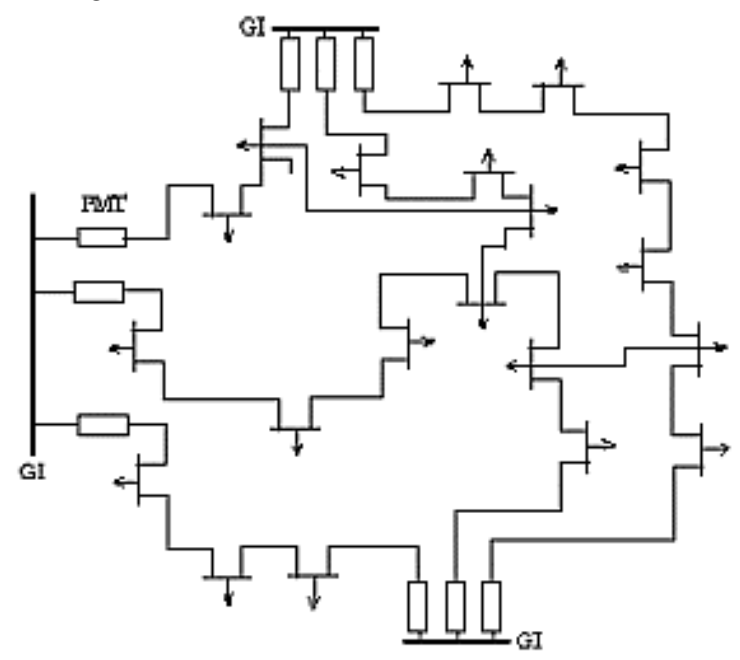

Fig. 1. . Interconnection System

\section{B. Power Flow}

The study of power flow is essential to a mathematical approach to determining the large and voltage angles on each bus, with the voltage being discovered, hence the active power $(\mathrm{P})$ and the reactive power $(\mathrm{Q})$ can be calculated. If $\mathrm{P}$ and $\mathrm{Q}$ on two buses are known, the power flow can be identified, including the loss-loss that is on the connected channel.

Three methods are often used in the calculation of power flow. For large-scale electric power systems, the NewtonRaphson method is a more efficient and practical method, where the number of iterations needed for fewer calculations is compared to other methods. In this method, the equation of power flow is formulated in the polar form [28]-[31].

$$
I_{i}=\sum_{j=1}^{n} Y_{i j} V_{j} \angle \theta_{i j}+\delta_{j} \text { untuk } i=1,2,3, n
$$

Active and reactive power on the bus-i are:

$$
P_{i}-j Q_{i}=V_{i}^{*} I_{i}
$$

By addressing (1) to (2) will be derived equations:

$$
P_{i}-j Q_{i}=\left|V_{i}\right| \angle-\delta_{i} \sum_{j=1}^{n}\left|Y_{i j}\right|\left|V_{j}\right| \angle \theta_{i j}+\delta_{j}
$$

The real and imaginary parts of the (3) are then separated

$$
\begin{gathered}
P_{i}=\sum_{j=1}^{n}\left|V_{i}\right|\left|V_{j}\right|\left|Y_{i j}\right| \cos \left(\theta_{i j}-\delta_{i}+\delta_{j}\right) \\
Q_{i}=-\sum_{j=1}^{n}\left|V_{i}\right|\left|V_{j}\right|\left|Y_{i j}\right| \sin \left(\theta_{i j}-\delta_{i}+\delta_{j}\right)
\end{gathered}
$$

The above equation was developed from the Taylor series as in the following equation.

$$
\left[\begin{array}{l}
\Delta P \\
\Delta Q
\end{array}\right]=\left[\begin{array}{ll}
J_{1} & J_{2} \\
J_{3} & J_{4}
\end{array}\right]\left[\begin{array}{c}
\Delta \delta \\
\Delta|V|
\end{array}\right]
$$

The calculations for the new phase angle and bus voltage are:

$$
\begin{gathered}
\delta^{(k+1)}=\delta_{i}^{(k)}+\Delta \delta_{i}^{(k)} \\
\left|V^{(k+1)}\right|=\left|V_{i}^{(k)}\right|+\Delta\left|V_{i}^{(k)}\right|
\end{gathered}
$$

\section{Static Stability Analysis}

The analysis of static stability (during steady-state) is usually used in the voltage instability problems caused by small disturbances, such as a load splash. The main study method used for static analysis is a simulated power flow. This method is divided into two, namely the P-V curve and the Q$\mathrm{V}$ curve. Both methods can determine the load limit on the steady-state associated with voltage stability.

The $\mathrm{P}-\mathrm{V}$ curve is a curve describing the relationship between the active power $(\mathrm{P})$ and the voltage $(\mathrm{V})$. The $\mathrm{P}-\mathrm{V}$ curve is obtained by conducting a simulated power flow where the load changes. This simulation will result in magnitude values of voltage and active power on a constantly changing bus forming a curve-shaped "nose" or nose. In Figure 2, it appears that the larger the active power is supplied on a system, the system voltage will be decreased. The active power supplied by the system starts at a value of $0 \mathrm{PU}$, and the voltage is at one pu. Then, when active power is added, the voltage will begin to decline. It continues to occur at a point called a critical point, where if the addition of power passes through this point will cause tension instability.

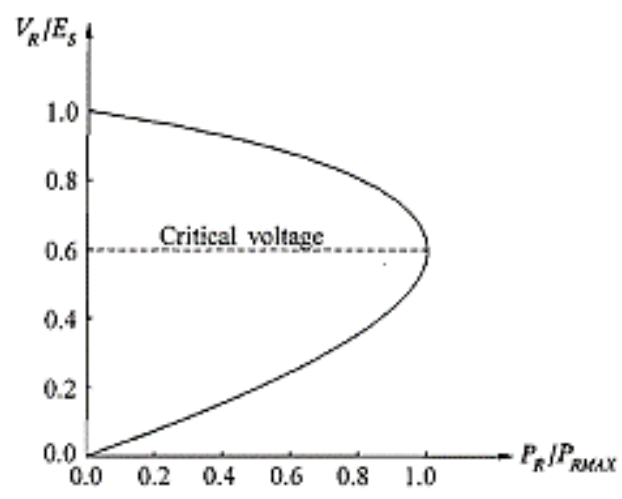

Fig. 2. P-V Curve

\section{Dynamic Stability Analysis}

Dynamic analysis is usually done by interfered with disruptions - a significant disruption to the system, including 
the release of generators and three-phase interference in the transmission line. The system's major disturbance voltage stability analysis can be done using a domain-based simulation of time or a transient simulation.

Transient simulation is performed for various scenarios of interference, and system behavior must be observed. If the system voltage returns to an acceptable value after clearing the disorder, the system is stable, but otherwise, the system voltage is unstable. Simulation needs to be done using Time Domain Analysis as the observation time can occur very briefly.

\section{E. Continuous Power Flow}

The Jacobian matrix of the power flow equation becomes singular at the voltage stability limit. Continuous Power Flow (CPF) solves this problem. CPF discovers a load-flow solution that participates in compliance with load scenarios. This method consists of predictive steps and corrections. From a known basic solution, a tangent predictor is used to estimate the next solution for a given load-pattern lift. The correction step then determines the appropriate solution using the Newton-Raphson technique used by conventional power streams. After that, a new prediction is made for a specific load increase based on the new tangent vector. Then the correction step is applied. This process lasts until a critical point is reached. An illustration of the Predictor scheme is depicted in Figure 3.

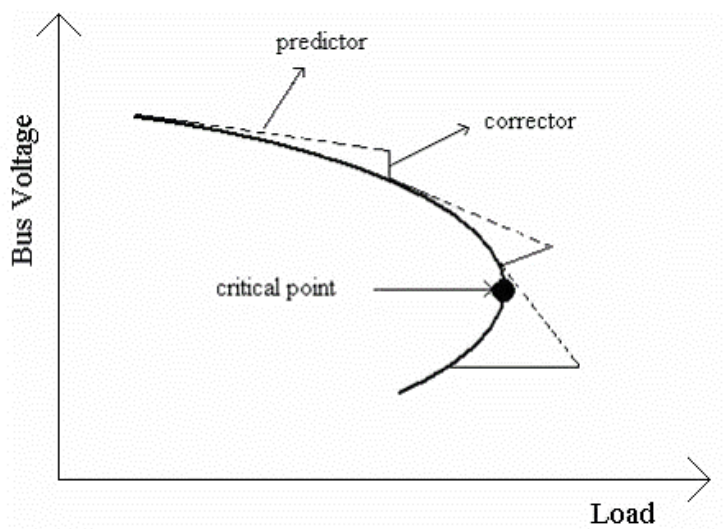

Fig. 3. Illustration of the Predictor-correctors step

In CPF, the equation of the first power stream is reformulated by inserting a load parameter into the equation its equation.

The power injected into the system for the I-Bus on the Nbus system can be written as follows:

$$
\begin{gathered}
P_{i}=\sum_{j=1}^{n}\left|V_{i}\right|\left|V_{j}\right|\left(G_{i j} \cos \theta_{i j}+B_{i j} \sin \theta_{i j}\right) \\
Q_{i}=\sum_{j=1}^{n}\left|V_{i}\right|\left|V_{j}\right|\left(G_{i j} \sin \theta_{i j}-B_{i j} \cos \theta_{i j}\right) \\
P_{i}=P_{G i}-P_{D i}, \quad Q_{i}=Q_{G i}-Q_{D i}
\end{gathered}
$$

The $G$ and $D$ subscripts in the equation signify the generation and demand for load in-between participating for the corresponding bus. The load- $\lambda$ parameter is inserted into the power request $\mathrm{P}_{\mathrm{Di}}$ and $\mathrm{Q}$ to simulate a load change, Di.

$$
\begin{gathered}
P_{D i}=P_{D i 0}+\lambda\left(P_{\Delta b a s e}\right) \\
Q_{D i}=Q_{D i 0}+\lambda\left(Q_{\Delta b a s e}\right)
\end{gathered}
$$

$\mathrm{P}_{\mathrm{Di} 0}$ and $\mathrm{Q}_{\mathrm{Di} 0}$ are the initial load requests on the i-bus, and the $\mathrm{P}_{\Delta \text { base }}$ and $\mathrm{Q}_{\Delta \text { base }}$ are the specific power values selected to scale the $\lambda$ properly. After addressing the equation (12) to the equation (11), the new equation can be represented as follows:

$$
F(\theta, V, \lambda)=0
$$

Where $\theta$ is a vector of bus voltage angles, and $\mathrm{V}$ is a vector of bus voltage magnitude. The primary solution for $\lambda=0$ can be obtained through the power stream. Then, the CPF and parameterization processes are applied.

\section{F. PSAT (Power System Analysis Toolbox) on MATLAB}

Power System Analysis Toolbox (PSAT) is the toolbox of MATLAB for the analysis and simulation of electrical power systems. All operations can be accessed using a graphical user interface (GUI), and a SIMULINK-based library provides the tools needed to design the network. Key features of PSAT include Power Flow (PF), continuous power Flow (CPF), optimal power flow, small-signal analysis (SSA), timedomain simulation, FACTS modeling, angina turbine models, and data conversion from multiple Format. Export results from this tool can be done to Microsoft Excel files and latex files.

\section{RESEARCH METHODS}

A. System Modeling

This type of research is an application of experimental research that is applicative so that from the scope of problems can be conducted the assessment with the method of literature studies, data collection methods (both in literature and field) followed by Design and modeling systems.

In this study, simulations were performed using PSAT software 2.1.10 (Power System Analysis Toolbox) in MATLAB R2018a. The network topology used is the IEEE 6 Bus network system.

Figure 4 is an IEEE 6 Bus network system image. The system consists of 3 bus generators (PV generators on bus 2 and 3, while bus one is installed slack bus as a reference bus). There are 11 transmission lines on this network system that connects each of the buses. The network-mounted loads are on buses 4,5 , and 6 .

\section{B. System Parameters}

In this research, the parameter needed in the system simulation is generator data, bus data, and transmission line data. These data can be seen in Tables 1,2, and 3, respectively.

\begin{tabular}{|l|l|l|l|l|l|l|}
\hline \multicolumn{7}{|c|}{ Table I. Generator Data } \\
\begin{tabular}{|l|l} 
No. \\
Gus/
\end{tabular} & $\begin{array}{c}\mathrm{P} \\
\text { Gen }\end{array}$ & $\begin{array}{c}\text { Q } \\
(\text { MVAR })\end{array}$ & $\begin{array}{c}\mathrm{P}_{\max } \\
(\mathrm{MW})\end{array}$ & $\begin{array}{c}\mathrm{P}_{\min } \\
(\mathrm{MW})\end{array}$ & $\begin{array}{c}\mathrm{Q}_{\max } \\
(\mathrm{MVAR})\end{array}$ & $\begin{array}{c}\mathrm{Q}_{\min } \\
(\mathrm{MVAR})\end{array}$ \\
\hline 1 & 0 & 0 & 200 & 50 & 100 & -100 \\
\hline 2 & 50 & 0 & 150 & 37.5 & 100 & -100 \\
\hline 3 & 60 & 0 & 180 & 45 & 100 & -100 \\
\hline
\end{tabular}




\begin{tabular}{|l|l|l|l|l|l|l|l|l|}
\multicolumn{10}{|c|}{ Table II. Bus Data [2] } \\
\begin{tabular}{|l|l|l|l|l|l|l|l|l|} 
No. \\
Bus
\end{tabular} & Tipe & $\begin{array}{l}V \\
\text { (p.u.) }\end{array}$ & $\begin{array}{l}\delta \\
\text { (p.u.) }\end{array}$ & $\begin{array}{l}\mathrm{P}_{\text {load }} \\
\text { (MW) }\end{array}$ & $\begin{array}{l}\mathrm{Q}_{\text {load }} \\
\text { (MVAR) }\end{array}$ & $\begin{array}{l}\mathrm{C}_{\text {shunt }} \\
\text { (MVAR) }\end{array}$ & $\begin{array}{l}\mathrm{V}_{\max } \\
\text { (p.u.) }\end{array}$ & $\begin{array}{l}\mathrm{V}_{\text {min }} \\
\text { (p.u.) }\end{array}$ \\
\hline 1 & SB & 1.05 & 0 & 0 & 0 & 0 & 1.1 & 0.9 \\
\hline 2 & PV & 1.05 & 0 & 0 & 0 & 0 & 1.1 & 0.9 \\
\hline 3 & PV & 1.07 & 0 & 0 & 0 & 0 & 1.1 & 0.9 \\
\hline 4 & PQ & 1 & 0 & 70 & 70 & 0 & 1.1 & 0.9 \\
\hline 5 & PQ & 1 & 0 & 70 & 70 & 0 & 1.1 & 0.9 \\
\hline 6 & PQ & 1 & 0 & 70 & 70 & 0 & 1.1 & 0.9 \\
\hline
\end{tabular}

Table III. Line Data [2]

Table III. Line Data [2]
\begin{tabular}{|l|l|l|l|l|l|}
\hline $\begin{array}{l}\text { No. } \\
\text { Line }\end{array}$ & $\begin{array}{l}\text { No.Hub. } \\
\text { Bus }\end{array}$ & $\begin{array}{l}\text { Resistance } \\
\text { (p.u.) }\end{array}$ & $\begin{array}{l}\text { Reactance } \\
\text { (p.u.) }\end{array}$ & $\begin{array}{l}\text { B } \\
\text { (p.u.) }\end{array}$ & $\begin{array}{l}\text { Maks. S } \\
\text { (MVA) }\end{array}$ \\
\hline 1 & $1-2$ & 0.1 & 0.2 & 0.04 & 40 \\
\hline 2 & $1-4$ & 0.05 & 0.2 & 0.04 & 60 \\
\hline 3 & $1-5$ & 0.08 & 0.3 & 0.06 & 40 \\
\hline 4 & $2-3$ & 0.05 & 0.25 & 0.06 & 40 \\
\hline 5 & $2-4$ & 0.05 & 0.1 & 0.02 & 80 \\
\hline 6 & $2-5$ & 0.1 & 0.3 & 0.04 & 30 \\
\hline 7 & $2-6$ & 0.07 & 0.2 & 0.05 & 90 \\
\hline 8 & $3-5$ & 0.12 & 0.26 & 0.05 & 70 \\
\hline 9 & $3-6$ & 0.02 & 0.1 & 0.02 & 90 \\
\hline 10 & $4-5$ & 0.2 & 0.4 & 0.08 & 20 \\
\hline 11 & $5-6$ & 0.1 & 0.3 & 0.06 & 40 \\
\hline
\end{tabular}

The network topology used in this study is the IEEE 6 Bus network system, as shown in Figure 4.

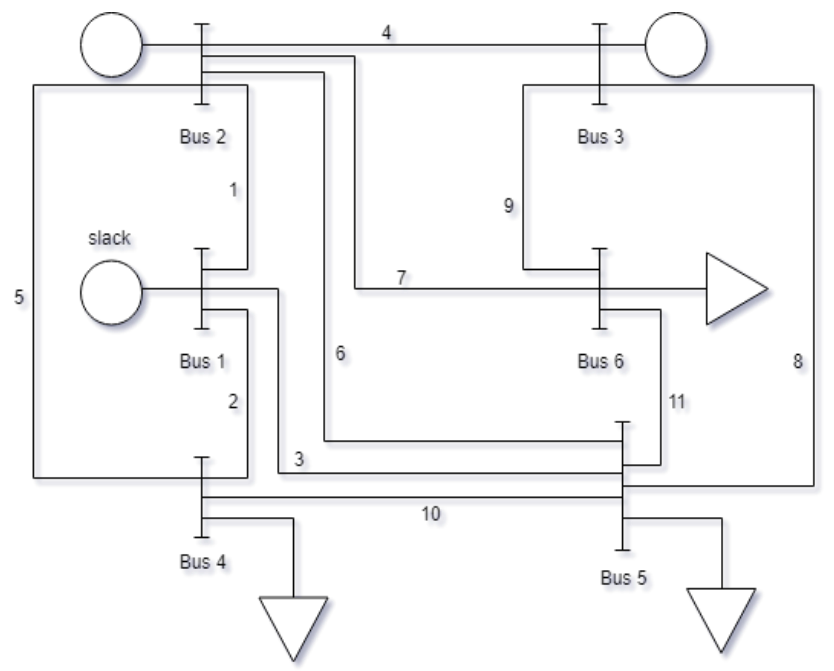

Fig 4. Single line diagram for six bus IEEE Network

\section{Research Procedure}

Based on the data that has been obtained and the system modelling that has been done, power flow simulation, static voltage stability analysis, and dynamic voltage stability analysis can then be performed using PSAT 2.1.10 / MATLAB R2018a software. Figure 5 shows the stages in analyzing the voltage stability of the power system with the continuous power flow method and time-domain analysis.

\section{RESULT AND DISCUSSION}

\section{A. Load Flow Analysis}

Power flow simulations are performed using the Power Flow menu in PSAT 2.1.10 / MATLAB R2018a. The Newton-Raphson method is used in this simulation. With a maximum iteration of 20 times and $10^{-5}$ tolerance. Table 4 shows the results of power flow simulations performed on the IEEE 6 bus network system.

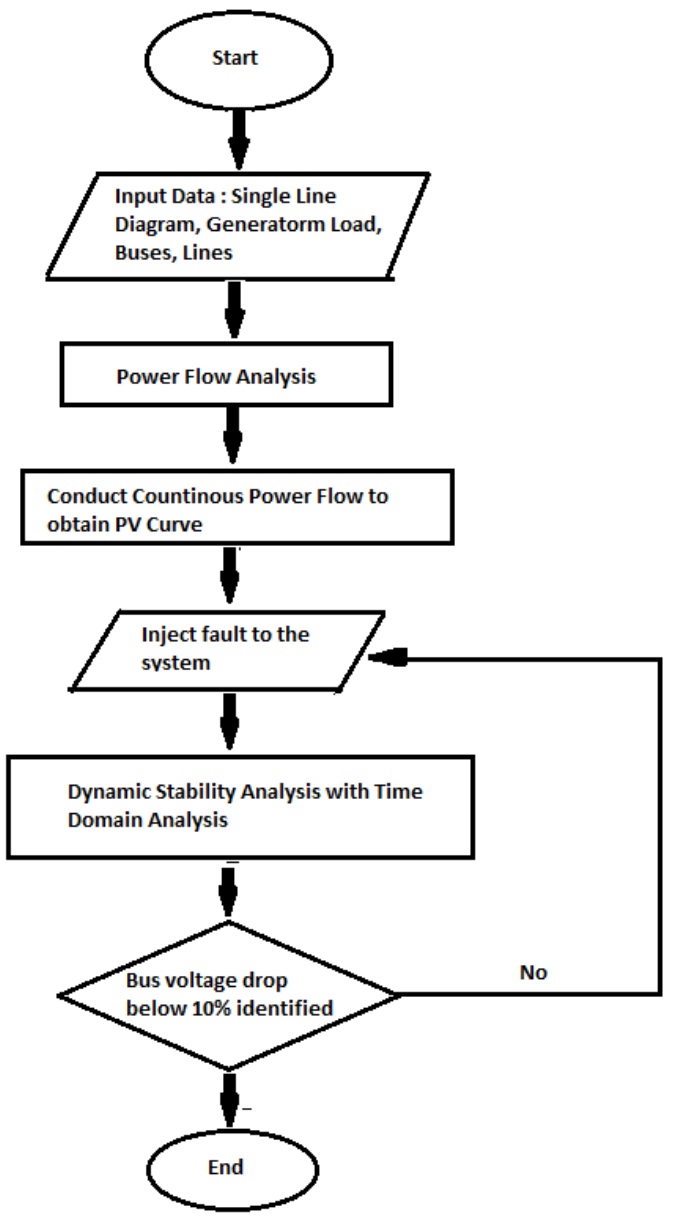

Fig. 5. Research flowchart

\begin{tabular}{|c|c|c|c|c|c|c|}
\hline \multirow{2}{*}{$\begin{array}{l}\text { No } \\
\text { Bus }\end{array}$} & \multirow{2}{*}{$\begin{array}{c}\mathrm{V} \\
\text { Nominal } \\
(\mathrm{kV})\end{array}$} & \multirow{2}{*}{$\begin{array}{c}\mathrm{V} \\
\text { (p.u) }\end{array}$} & \multirow{2}{*}{$\begin{array}{l}\text { V } \\
\text { drop } \\
(\%)\end{array}$} & \multirow{2}{*}{$\delta\left({ }^{\circ}\right)$} & \multicolumn{2}{|c|}{ Power } \\
\hline & & & & & $\begin{array}{l}\text { Active } \\
\text { (MW) }\end{array}$ & $\begin{array}{l}\text { Reactive } \\
\text { (MVAR) }\end{array}$ \\
\hline 1 & 11 & 1.05 & -5 & 0 & 107.88 & 15.96 \\
\hline 2 & 11 & 1.05 & -5 & -3.67 & 50 & 74.36 \\
\hline 3 & 11 & 1.07 & -7 & -4.27 & 60 & 89.63 \\
\hline 4 & 11 & 0.989 & 1.1 & -4.20 & -70 & -70 \\
\hline 5 & 11 & 0.985 & 1.5 & $\begin{array}{l}-5.28 \\
\end{array}$ & -70 & -70 \\
\hline 6 & 11 & 1.004 & -0.4 & -5.95 & -70 & -70 \\
\hline
\end{tabular}

The table shows that the most significant voltage drop occurred on bus five, which is $1.5 \%$, but the whole bus is still in normal condition because the voltage drop is not more than $10 \%$. The total active power $(\mathrm{P})$ and reactive power $(\mathrm{Q})$ generated by the system are 217.88 MW and 179.95 MVAR respectively, while the total active power $(\mathrm{P})$ load and reactive power load (Q) drawn by the system respectively $210 \mathrm{MW}$ and 210 MVAR. Table 5 shows the load flow on the transmission line.

The simulation results show there is a 30.05 MVAR lack of reactive power. This deficiency can be overcome by the presence of line charging that arises as a result of the presence of a line susceptance (B). Based on the results, the total line charging provided by the line is 54.2 MVAR, so the total reactive power generated by the system is 234.15 MVAR. The total power losses in the system are 7.88 MW and 24.15 MVAR. 
Table V. Load flow on transmission line

\begin{tabular}{|c|c|c|c|c|c|c|c|c|}
\hline \multirow[t]{2}{*}{ No. } & \multirow{2}{*}{$\begin{array}{c}\text { From } \\
\text { Bus }\end{array}$} & \multirow{2}{*}{$\begin{array}{c}\text { To } \\
\text { Bus- }\end{array}$} & \multicolumn{2}{|c|}{ Power deliver } & \multicolumn{2}{|c|}{ Power received } & \multicolumn{2}{|c|}{$\begin{array}{c}\text { Losses } \\
\left(I^{2} * Z\right)\end{array}$} \\
\hline & & & $\begin{array}{c}\mathrm{P} \\
(\mathrm{MW})\end{array}$ & $\begin{array}{c}\mathrm{Q} \\
\text { (MVAR) }\end{array}$ & $\begin{array}{c}\mathrm{P} \\
(\mathrm{MW})\end{array}$ & $\begin{array}{c}\mathrm{Q} \\
\text { (MVAR) }\end{array}$ & $\begin{array}{c}\mathrm{P} \\
(\mathrm{MW})\end{array}$ & $\begin{array}{c}\mathrm{Q} \\
\text { (MVAR) }\end{array}$ \\
\hline 1 & 1 & 2 & 28.69 & -15.42 & -27.78 & 12.82 & 0.905 & 1.81 \\
\hline 2 & 1 & 4 & 43.58 & 20.12 & -42.50 & -19.93 & 1.088 & 4.35 \\
\hline 3 & 1 & 5 & 35.60 & 11.25 & -34.53 & -13.45 & 1.074 & 4.03 \\
\hline 4 & 2 & 3 & 2.93 & -12.27 & -2.89 & 5.73 & 0.040 & 0.20 \\
\hline 5 & 2 & 4 & 33.09 & 46.05 & -31.59 & -45.13 & 1.505 & 3.01 \\
\hline 6 & 2 & 5 & 15.51 & 15.35 & -15.02 & -18.01 & 0.498 & 1.49 \\
\hline 7 & 2 & 6 & 26.25 & 12.40 & -25.67 & -16.01 & 0.583 & 1.67 \\
\hline 8 & 3 & 5 & 19.12 & 23.17 & -18.02 & -26.10 & 1.094 & 2.37 \\
\hline 9 & 3 & 6 & 43.77 & 60.72 & -42.77 & -57.86 & 1.003 & 5.02 \\
\hline 10 & 4 & 5 & 4.08 & -4.94 & -4.05 & -2.79 & 0.036 & 0.07 \\
\hline 11 & 5 & 6 & 1.61 & -9.66 & -1.56 & 3.87 & 0.050 & 0.15 \\
\hline & & & & & & Total $=$ & 7.875 & 24.15 \\
\hline
\end{tabular}

From Table 6, it can be observed that the total active and reactive power losses for each load bus are $2.59 \mathrm{MW}$ / 7.36MVAR, 2.67MW / 7.89MVAR, and $1.59 \mathrm{MW} \mathrm{/}$ 6.69MVAR for buses 4,5 , and 6 , respectively.

Table VI. Load flow Bus Generator to Load bus

\begin{tabular}{|c|c|c|c|c|c|c|}
\hline \multirow{2}{*}{$\begin{array}{c}\text { From } \\
\text { Bus }\end{array}$} & \multirow{2}{*}{$\begin{array}{c}\text { To } \\
\text { Bus- }\end{array}$} & \multirow{2}{*}{$\begin{array}{c}\begin{array}{c}\text { Line } \\
\text { Impedance }\end{array} \\
\mathrm{R}+\mathrm{jX} \\
\text { (p.u.) }\end{array}$} & \multicolumn{2}{|c|}{ Load Flow } & \multicolumn{2}{|c|}{ Losses } \\
\hline & & & $\begin{array}{c}\mathrm{P} \\
(\mathrm{MW})\end{array}$ & $\begin{array}{c}\mathrm{Q} \\
\text { (MVAR) }\end{array}$ & $\begin{array}{c}\mathrm{P} \\
(\mathrm{MW})\end{array}$ & $\begin{array}{c}\mathrm{Q} \\
\text { (MVAR) }\end{array}$ \\
\hline \multirow[t]{2}{*}{1} & 4 & $0.05+\mathrm{j} 0.2$ & 43.58 & 20.12 & 1.088 & 4.35 \\
\hline & 5 & $0.08+\mathrm{j} 0.3$ & 35.60 & 11.25 & 1.074 & 4.03 \\
\hline \multirow[t]{3}{*}{2} & 4 & $0.05+\mathrm{j} 0.1$ & 33.09 & 46.05 & 1.505 & 3.01 \\
\hline & 5 & $0.1+\mathrm{j} 0.3$ & 15.51 & 15.35 & 0.498 & 1.49 \\
\hline & 6 & $0.07+0.2$ & 26.25 & 12.40 & 0.583 & 1.67 \\
\hline \multirow[t]{2}{*}{3} & 5 & $0.12+\mathrm{j} 0.26$ & 19.12 & 23.17 & 1.094 & 2.37 \\
\hline & 6 & $0.02+\mathrm{j} 0.1$ & 43.77 & 60.72 & 1.003 & 5.02 \\
\hline
\end{tabular}

Bus 5 has the highest power losses compared to other buses because this bus has the highest line impedance (as shown in Table 3), which congruent with the fact that bus 5 has the highest voltage drop.

\section{B. Static Stability Analysis}

Static voltage stability analysis can be done by observing the PV curve for each load bus in the system. The simulation carried out to obtain this PV curve is by carrying out continuous power flow (CPF), which is a continuous power flow analysis continuously on a system with an increasing load changing value. In this study, CPF simulations are performed with the CPF menu in PSAT 2.1.10 / MATLAB R2018a software, with the basic load used is the load when performing a previous power flow analysis. Figure PV curve results from the simulation can be seen in Figure 5.

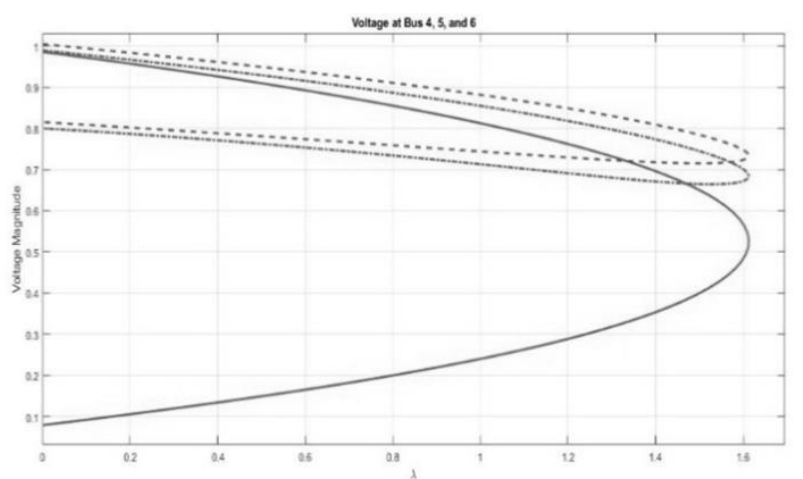

Fig. 5. P-V curve simulation results
The load margin $(\lambda)$ value obtained from the simulation is 1.6130. A load margin is a measure or distance of the fundamental closeness of a system to voltage collapse. $\lambda$ max $=1.6130$ means the system can bear the maximum load increase of $160.13 \%$ of the initial load. It can be said that if the system has a larger load margin means that the system has good voltage stability against small disturbances (increased load).

From equation (12), the maximum load that can be accommodated by the system (for each load) before a voltage collapses or a voltage drop outside the allowable limit is:

$$
\begin{aligned}
& P_{i}=P_{0}+\lambda P_{0}=70 \mathrm{MW}+1.6130 \times 70 \mathrm{MW}=181.91 \mathrm{MW} \\
& Q_{i}=Q_{0}+\lambda Q_{0}=70 \mathrm{MVAR}+1.6130 \times 70 \mathrm{MVAR}=181.91 \mathrm{MVAR}
\end{aligned}
$$

Based on the PV curve in Figure 5, it can be noted that the bus that has the lowest level of voltage stability is bus 5. As explained earlier, this is because each line leading to bus 5 has the highest impedance when compared to the line to the other load bus, so the power losses become highest. With significant line losses, the voltage drop is even greater.

\section{Dynamic Stability Analysis}

Dynamic voltage stability simulation is performed using the Time Domain menu on PSAT 2.1.10 / MATLAB R2018a. The simulation is carried out with two types of interference: (1) line termination; (2) disturbances or faults in the load bus. The simulation is done by terminating line 1 to line 11 on the system one by one in a row. Changes in voltage values for each load bus after line termination can be seen in Table 7 .

Table VII. Voltage values at each load after line cut-off

Table VII. Voltage values at each load after line cut-off
\begin{tabular}{|c|c|c|c|c|c|c|}
\hline \multirow{2}{*}{$\begin{array}{c}\text { Number } \\
\text { of } \\
\text { outage } \\
\text { line }\end{array}$} & \multicolumn{7}{|c|}{ Voltage (p.u.) } \\
\cline { 2 - 8 } & Bus 1 & Bus 2 & Bus 3 & Bus 4 & Bus 5 & Bus 6 \\
\hline 1 & 1.02 & 1.03 & 1.05 & 0.97 & 0.96 & 0.98 \\
\hline 2 & 1.08 & 1.04 & 1.06 & 0.95 & 0.98 & 1.00 \\
\hline 3 & 1.06 & 1.03 & 1.05 & 0.98 & 0.95 & 0.98 \\
\hline 4 & 1.03 & 1.03 & 1.06 & 0.97 & 0.97 & 0.99 \\
\hline 5 & 1.03 & 1.09 & 1.09 & 0.91 & 0.99 & 1.02 \\
\hline 6 & 1.04 & 1.05 & 1.06 & 0.98 & 0.96 & 0.99 \\
\hline 7 & 1.05 & 1.05 & 1.05 & 0.99 & 0.98 & 0.97 \\
\hline 8 & 1.03 & 1.04 & 1.08 & 0.97 & 0.95 & 1.00 \\
\hline 9 & 1.05 & 1.05 & 1.16 & 0.99 & 0.99 & 0.92 \\
\hline 10 & 1.03 & 1.03 & 1.05 & 0.97 & 0.96 & 0.99 \\
\hline 11 & 1.03 & 1.04 & 1.06 & 0.97 & 0.96 & 0.99 \\
\hline
\end{tabular}


From Table 7, it can be seen that from all the scenarios carried out, there is no voltage drop, which is below $10 \%$ of its normal value. Therefore, indicates that the system voltage is still stable against major disruptions in the form of line termination. However, it can be observed, the greatest voltage drops of all line disconnection scenarios carried out is in termination of lines 5 and 9 , which results in a voltage drop of $9 \%$ on bus 4 and $8 \%$ on bus 6 .

In the case where line 5 is disconnected, there is a large voltage drop on bus $4(9 \%)$ due to the largest reactive power supply line injected into bus four is cut off. From the power flow analysis conducted previously (table 4.6), it is known that line 5 supplies reactive power of $46.05 \mathrm{MVAR}$, or at $66 \%$ of the total bus reactive power requirements 4 (70 MVAR). This loss of reactive power supply is compensated as much as possible by the supply from generator one and other generators through the line that passes bus 5, causing a higher voltage drop.

The same thing occurred when line 9 is disconnected of which caused a voltage drop on bus 6 of $8 \%$. In this case, the interrupted reactive power supply is $60.72 \mathrm{MVAR}$ or $86 \%$ of the reactive power requirements on bus 6 . Loss of this reactive power supply is compensated as much as possible by the supply from generator two and other generators through the channel passing bus 5, causing a greater voltage drop. The voltage dynamic stability profile for load bus when line 5 interrupted is shown in Figure 6.

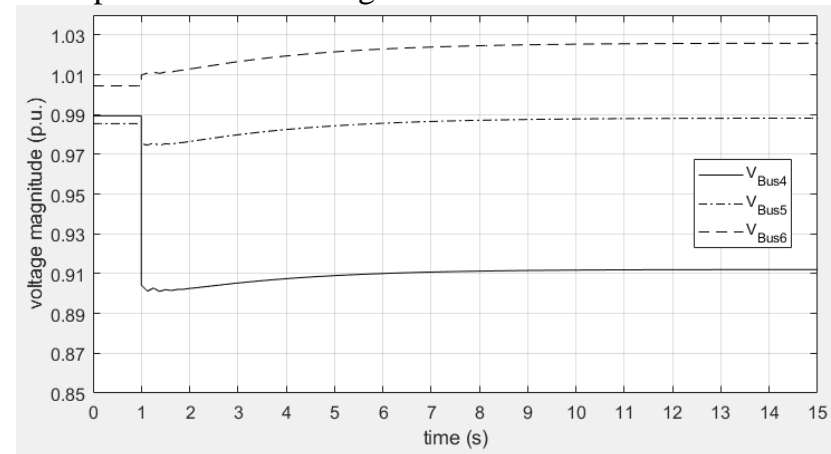

Fig. 6. Voltage stability when line 5 interrupted

Observation of dynamic voltage stability behavior is carried out by simulating the giving of faults or disturbances to the load bus one by one and not simultaneously. Termination of interruption on the bus is assumed to occur at $\mathrm{t}=1$ second and fault clearing time at 0.2 seconds and 0.4 seconds. Transient stability analysis for each bus is observed. For bus disturbances that occur on buses 4, 5, and 6 with fault clearing time within 0.2 seconds, a nominal voltage can be seen in Table 8 , with a representation of the dynamic voltage stability behavior depicted in Figure 7.

Table VIII. Voltage values for each bus for faults in each bus with a 0.2 second fault clearing time

\begin{tabular}{|c|l|c|c|c|c|c|c|}
\hline \multicolumn{2}{|c|}{} & $\begin{array}{c}\text { V1 } \\
\text { (p.u.) }\end{array}$ & $\begin{array}{c}\text { V2 } \\
\text { (p.u.) }\end{array}$ & $\begin{array}{c}\text { V3 } \\
\text { (p.u.) }\end{array}$ & $\begin{array}{c}\text { V4 } \\
\text { (p.u.) }\end{array}$ & $\begin{array}{c}\text { V5 } \\
\text { (p.u.) }\end{array}$ & $\begin{array}{c}\text { V6 } \\
\text { (p.u.) }\end{array}$ \\
\hline Before Fault & 1.05 & 1.05 & 1.07 & 0.989 & 0.985 & 1.004 \\
\hline \multirow{5}{*}{ After Fault } & $\begin{array}{l}\text { Bus } \\
4\end{array}$ & 1.048 & 1.049 & 1.069 & 0.988 & 0.984 & 1.003 \\
\cline { 2 - 9 } & $\begin{array}{l}\text { Bus } \\
5\end{array}$ & 1.048 & 1.049 & 1.069 & 0.988 & 0.984 & 1.003 \\
\cline { 2 - 8 } & $\begin{array}{l}\text { Bus } \\
6\end{array}$ & 1.048 & 1.049 & 1.069 & 0.988 & 0.984 & 1.003 \\
\hline
\end{tabular}

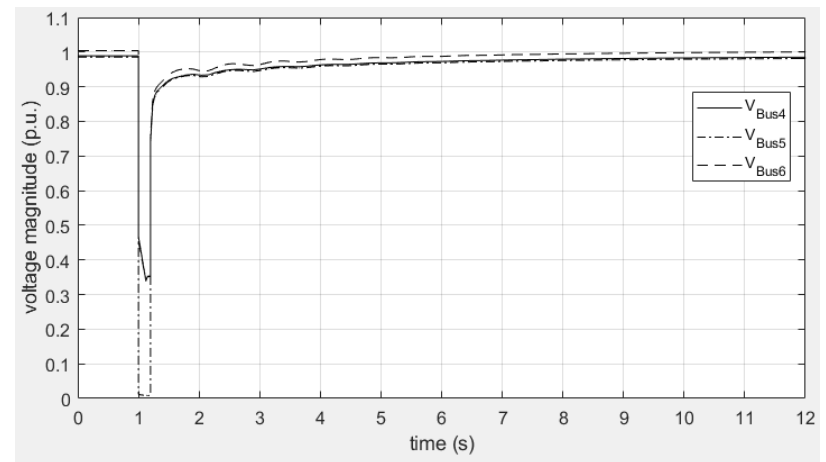

Fig. 7. Dynamic voltage stability on bus 4-6 for a disturbance on bus 5 with a fault clearing time of 0.2 seconds

For bus interruptions that occur on bus 4 with a fault clearing time of 0.4 seconds, the nominal voltage can be seen in Table 9, with a description of its dynamic voltage stability behavior that can be seen in Figure 8 .

The result shows that after experiencing a disruption with a longer clearing time, the system cannot return to its stable state. With bus 1 experiencing a voltage collapse and other buses experiencing a very significant voltage drop, which indicates that the transient stability of the system is at a critical breaker time below 0.4 seconds.

Table IX. Voltage values for each bus for faults on bus 4 with a fault clearing time of 0.4 seconds

\begin{tabular}{|c|c|c|c|c|c|c|}
\hline & $\begin{array}{c}\text { V1 } \\
\text { (p.u.) }\end{array}$ & $\begin{array}{c}\text { V2 } \\
\text { (p.u.) }\end{array}$ & $\begin{array}{c}\text { V3 } \\
\text { (p.u.) }\end{array}$ & $\begin{array}{c}\text { V4 } \\
\text { (p.u.) }\end{array}$ & $\begin{array}{c}\text { V5 } \\
\text { (p.u.) }\end{array}$ & $\begin{array}{c}\text { V6 } \\
\text { (p.u.) }\end{array}$ \\
\hline $\begin{array}{c}\text { Before } \\
\text { Fault }\end{array}$ & 1.05 & 1.05 & 1.07 & 0.989 & 0.985 & 1.004 \\
\hline $\begin{array}{c}\text { After } \\
\text { Fault }\end{array}$ & 1.048 & 1.049 & 1.069 & 0.988 & 0.984 & 1.003 \\
\hline
\end{tabular}

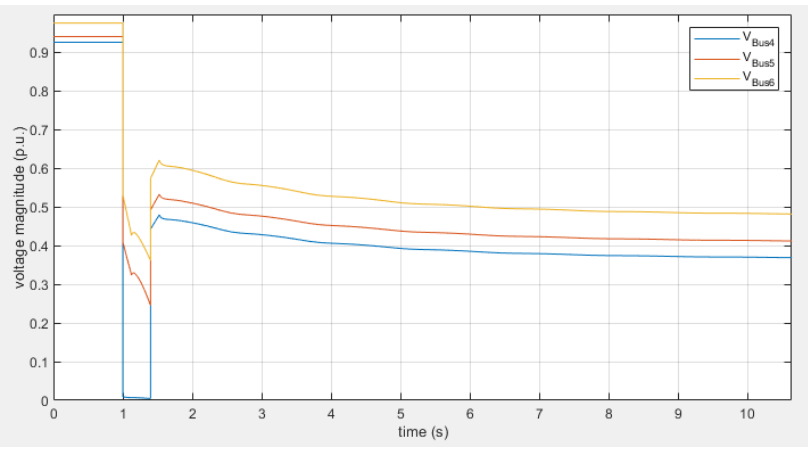

Fig. 8. Dynamic voltage stability on bus 4-6 for when bus 4 interrupted with a fault clearing time of 0.4 seconds

For disturbance on Bus 5, assuming a fault clearing time of 0.4 seconds, the voltage behavior for each bus is almost the same as if there is a disturbance on bus 4 . However, for interference on Bus 6 assuming a fault clearing time of 0.4 seconds, the simulation experiences a singularity due to the system voltage collapses on each bus so that the system cannot be returned to its operating state.

\section{CONCLUSION}

Voltage stability analysis using Continuous Power Flow and Time Domain Analysis can provide a more comprehensive overview of a power system stability level. 
The bus voltage profiles obtained by simulating a power flow are all in normal conditions, i.e., they do not encounter a voltage drop below $10 \%$. Nevertheless, bus 5 reached the highest decrease in voltage with a value of $1.5 \%$. The results in the power flow simulation are in line with the PV curve obtained from the continuous power flow, where bus 5 has the lowest stability level.

The results showed the value of the load margin $(\lambda)$ is 1.6130 , means that the loading value that can be applied to a load bus before the voltage on the bus experiences a voltage collapse is $160.13 \%$ of its initial load, i.e., 181.91 MW with a power factor of 0.707 .

Simulating system interference performed the dynamic evaluation of voltage stability. Also, a study of the time domain is carried out because the measurement process will take place very briefly. The results of the simulation show that the tested power system has a clearing time of under 0.4 seconds

\section{REFERENCES}

[1] M. Vaiman and M. Vaiman, "Determining the most dangerous direction of power system stressing," in 2018 IEEE Power \& Energy Society Innovative Smart Grid Technologies Conference (ISGT), 2018, vol. 5, pp. 1-5.

[2] H. V. Q. Luu, "Modeling the Transient Energy Margin for Accessing the Transient Stability with Double Shot Automatic Line Reclosing in Power System," in 2018 International Conference on Advanced Computing and Applications (ACOMP), 2018, pp. 29-34.

[3] H. Suyono, M. Shidiq, A. N. Ferdianzah, T. Utomo, I. Musirin, and L. J. Awalin, "Dynamic Stability Impact of the Hybrid Wind and Microhydro Renewable Energy Sources on the Distribution System," in 2018 Electrical Power, Electronics, Communications, Controls and Informatics Seminar (EECCIS), 2018, pp. 15-20.

[4] Y. Wang, A. Xue, K. Luo, J. Zhou, J. Xu, and J. Cui, “Analyses on the Adaptability of the Branch Voltage Stability Index in the Distribution Network Interconnected with PV," in 2018 International Conference on Power System Technology (POWERCON), 2018, no. 201804270000133, pp. 1224-1228.

[5] Z. Hu, W. Wu, M. Li, and Z. Lin, "VSC-HVDC Power Control Strategy for Improving Voltage Stability of AC-DC Power Grid," in 2018 2nd IEEE Conference on Energy Internet and Energy System Integration (EI2), 2018, pp. 1-5.

[6] Z. Jianjun, S. Dongyu, Z. Dong, and G. Yang, "Load Shedding Control Strategy for Power System Based on the System Frequency and Voltage Stability(Apr 2018)," in 2018 China International Conference on Electricity Distribution (CICED), 2018, no. 201804230000057 , pp. 1352-1355.

[7] S. Helm, E. G. Otto, I. Hauer, and M. Wolter, "Intelligent decentralized approach for reactive power compensation by VSC converter," in 2018 53rd International Universities Power Engineering Conference (UPEC), 2018, pp. 1-6.

[8] X. Wang, P. C. Loh, and F. Blaabjerg, "Stability Analysis and Controller Synthesis for Single-Loop Voltage-Controlled VSIs," IEEE Trans. Power Electron., vol. 32, no. 9, pp. 7394-7404, Sep. 2017.

[9] M. H. Haque, "Impacts of fixed speed wind generators on static voltage stability of distribution systems," in 2016 4th International Conference on the Development in the in Renewable Energy Technology (ICDRET), 2016, vol. 2, no. 2, pp. 1-6.

[10] H. Zhang, C. Xia, P. Peng, N. Chen, and B. Gao, "Research on the Voltage Regulation Strategy of Photovoltaic Power Plant," in 2018 China International Conference on Electricity Distribution (CICED), 2018, no. 201805240000009, pp. 1620-1624.

[11] D. Yang, X. Wang, and F. Blaabjerg, "Fast Power Control for VSCs to Enhance the Synchronization Stability in Ultra-Weak Grids," in 2018 IEEE Power \& Energy Society General Meeting (PESGM), 2018, pp. 1-6.

[12] F. Hu et al., "Measurement-based voltage stability assessment and control on CURENT hardware test bed system," in 2016 IEEE Power and Energy Society General Meeting (PESGM), 2016, vol. 2016Novem, pp. 1-5.

[13] Z. Zou, G. Buticchi, M. Liserre, A. M. Kettner, and M. Paolone, "Voltage stability analysis using a complete model of grid-connected voltage-source converters," in 2016 IEEE Energy Conversion Congress and Exposition (ECCE), 2016, pp. 1-8.

[14] M. Sagara, M. M. Sediqi, T. Senjyu, M. S. S. Danish, and T. Funabashi, "Voltage stability improvement by optimal active power and reactive power output control of storage battery system," in 2016 IEEE Region 10 Conference (TENCON), 2016, pp. 2671-2674.

[15] Yu Zhang, Xiaohui Song, Fei Gao, and Jianfang Li, "Research of voltage stability analysis method in distribution power system with plug-in electric vehicle," in 2016 IEEE PES Asia-Pacific Power and Energy Engineering Conference (APPEEC), 2016, vol. 2016-Decem, no. 51177152, pp. 1501-1507.

[16] A. Sajadi, R. M. Kolacinski, and K. A. Loparo, "Transient voltage stability of offshore wind farms following faults on the collector system," in 2016 IEEE Power and Energy Conference at Illinois (PECI), 2016, pp. 1-5.

[17] D. Lu, X. Wang, and F. Blaabjerg, "Impedance-based analysis of DC link control in voltage source rectifiers," in 2018 IEEE Applied Power Electronics Conference and Exposition (APEC), 2018, vol. 2018March, pp. 931-937.

[18] H. Jiang and C. Zhang, "Coordinated Control Scheme for Superconducting Magnetic Energy Storage Unit to Boost Transient Stability of Wind Farm Connected Power System," in 2018 IEEE International Conference on Applied Superconductivity and Electromagnetic Devices (ASEMD), 2018, no. 51477115, pp. 1-2.

[19] S. Hattori, H. Eto, J. Wang, and F. Kurokawa, "Experimental Verification of DC Bus Voltage Stability for Household Distributed Power System With Micro EV Battery," in 2018 7th International Conference on Renewable Energy Research and Applications (ICRERA), 2018, vol. 5, pp. 1325-1329.

[20] B. Baydar, M. C. Taplamacioglu, and H. Gozde, "Investigation of the effect of renewable energy sources on static voltage stability with dynamic optimal power flow solution in power systems," in 2018 th International Istanbul Smart Grids and Cities Congress and Fair (ICSG), 2018, pp. 203-207.

[21] S. D. Choudante and A. A. Bhole, "A Review: Voltage Stability and Power Flow Improvement by Using UPFC Controller," in 2018 Internat2018 International Conference on Computation of Power, Energy, Information and Communication (ICCPEIC)ional conference on computation of power, energy, Information and Communication (ICCPEIC), 2018, pp. 462-465.

[22] S. S. Asghari, P. Rabbanifar, S. A. Asghari, and D. Azizi, "A multiobjective optimal power flow model for transient and voltage stability improvement," in 2017 IEEE 7th International Conference on Power and Energy Systems (ICPES), 2017, vol. 2017-Decem, pp. 80-84.

[23] Q. Wang, Y. Guo, J. Yu, D. Zhang, J. Wan, and J. Zhong, "Monitoring the Voltage Stability Margin Using Norton Current Distribution Relationship," in 2018 IEEE Power \& Energy Society General Meeting (PESGM), 2018, pp. 1-5.

[24] Z. Qiao, Q. Guo, H. Sun, L. Jia, and W. Zhao, "Static voltage stability margin considering the coupling of natural gas and power system," in 2018 IEEE Power \& Energy Society General Meeting (PESGM), 2018, pp. 1-5.

[25] H. Liu, K. Ganesan, M. Zarzhami, A. Yazdani, and R. Nuqui, "RealTime Dynamic Voltage Stability Assessment Through a Wide-Area Loss Index," in 2018 IEEE Electrical Power and Energy Conference (EPEC), 2018, pp. 1-6.

[26] O. el fadhel loubaba Bekri and F. Mekri, "Impact Of Wind Turbine On Voltage Stability," in 2018 International Conference on Wind Energy and Applications in Algeria (ICWEAA), 2018, pp. 1-5.

[27] H. H. Eldeeb and O. A. Mohammed, "Control and Voltage Stability of A Medium Voltage DC Micro-Grid Involving Pulsed Load," in 2018 IEEE International Conference on Environment and Electrical Engineering and 2018 IEEE Industrial and Commercial Power Systems Europe (EEEIC / I\&CPS Europe), 2018, pp. 1-6.

[28] E. Glende, M. Wolter, B. Arendarski, P. Lombardi, and P. Komarnicki, "Optimal operational management methods of voltage 
control with a high feed of renewable energy sources," in 2018 IEEE International Energy Conference (ENERGYCON), 2018, pp. 1-6.

[29] A. K. Sinha and A. Amita, "Transient Stability Improvement of Grid Using Photo-Voltaic Solar Farm," in 2018 International Conference on Intelligent Circuits and Systems (ICICS), 2018, pp. 366-371.

[30] S. M. Said, B. Hartmann, M. M. Aly, M. Mosa, and R. S. Balog, "Comparison between operating modes of distributed generation on voltage profile and stability of distribution systems," in 2018 IEEE Texas Power and Energy Conference (TPEC), 2018, pp. 1-6.

[31] D. Peralta, C. Canizares, and K. Bhattacharya, "Practical Modeling of Flywheel Energy Storage for Primary Frequency Control in Power Grids," in 2018 IEEE Power \& Energy Society General Meeting (PESGM), 2018, no. November 2017, pp. 1-5. 